\title{
EMU Membership and Business Cycle Phases in Europe: Markov-Switching VAR Analysis
}

\author{
Michel Beine \\ Université of Lille 2 and Université Libre de Bruxelles \\ Bertrand Candelon \\ University Maastricht \\ Khalid Sekkat \\ Univervité Libre de Bruxelles and European Commission
}

\begin{abstract}
Most empirical applications of the OCA approach based on asymmetric shocks have failed to account for the credibility aspects that play an important role in deciding to join the EMU from the EMS or the EMS-BIS. In this paper, we tackle this problem by relying on a regime switching approach that characterizes the position of each economy in its business cycle. Then, using desynchronisation indices based on a non parametric approach, we measure the amplitude and the duration of divergence in the business cycles in order to assess the potential stabilization cost induced by the European economic and monetary union.
\end{abstract}

- JEL Classifications: E32, F31, F43

- Key words: Business cycle, OCA, Switching regines

\footnotetext{
*Corresponding address: Professor Michel Beine, Université of Lille 2 and Université Libre de Bruxelles, 50, Avenae F.D Roosevelt 1050 Brussels, Belgium, Tel: +32-2-650-4256, Fax: +32-2-650-3825, E-mail: mbeine@ulb.ac.be. Professor Bertrand Candelon, University Maastricht, Department of Economics, E-mail: candelon@agec.unimaas.nl. Professor Khalid Sekkat, Univervité Libre de Bruxelles and European Commission, E-mail: ksekkat@ulb.ac.be

(C)2003-Center for International Economics, Sejong Institution, All Rights Reserved.
} 


\section{Introduction}

The third and final stage of the Economic and Monetary Union (EMU) in Europe started on the first of January 1999. The Euro became the single and official currency of the eleven participating countries. At the same time monetary policy was transferred to a single authority, i.e. the European Central Bank (ECB). As a consequence, national policy makers are deprived of two stabilization instruments: monetary policy conducted at the national level and intra-European nominal exchange rate adjustments. Some non-member European countries like Denmark, Sweden or Greece have already announced their desire to join EMU in the future. The situation is much less clear for the United Kingdom.

For two decades, the traditional theory of optimum currency areas (OCA henceforth) has been the usual approach to assess the net benefits obtained from the creation of EMU. Basically, this approach balances the stabilization cost of losing the nominal exchange rate against the gains (reducing transaction costs, exchange rate variability, seigneurage ...). ${ }^{1}$ In that respect, the traditional approach is best suited when the alternative to monetary union is a pure flexible exchange rate system in which the equilibrium value is consistent with the equilibrium of the (bilateral) balance of payments. In the European case however, the alternative to EMU was rather a fixed and adjustable exchange rate system, i.e. the European Monetary System (EMS), although this may be less obvious for the UK. To a certain extent, the same situation prevails for most of the future candidate members to EMU, although this may be less true for the UK. At the Dublin Council, Denmark and Greece have already reached an agreement with the ECB on the management of their currency against the Euro. ${ }^{2}$ While following a strategy of inflation targeting, the Swedish central bank also aims at narrowing the interest rate spread over the ECB's refinancing rates, in the context of a long-term objective of EMU adhesion. ${ }^{3}$ In the case of Norway, the stability of the exchange

${ }^{1}$ See De Grauwe (1994) for a clear exposition.

${ }^{2}$ Since the 1st of January 1999, the Danish Krone and the Greek Drachma are linked to the Euro through a new currency mechanism called EMS-BIS or ERM2. The fluctuations bands are respectively $\pm 2.25 \%$ and $\pm 15 \%$. In the Danish case, the explicit objective is to reduce the risk premium incorporated in the interest rates see (OECD 1999a). The European Commission is expected to reach a decision on Greece's admission to EMU by June 2000.

${ }^{3} \mathrm{~A}$ decision on the willingness to join EMU should be taken by the end of 2001. Nevertheless, the Swedish policy mix aims at following the European requirements. Beyond monetary policy, the objective of fiscal policy is consistent with the criterion of the Growth and Stability Pact (see OECD 1999b). 
rate against the European currencies is also an explicit objective of monetary policy (see OECD 1999c).

Basically, the rationality for such strategies of "tying one's hands" is twofold. The first one is that such a fixed exchange rate system is helpful in building its own credibility and therefore favors inflation and interest rates convergence, as illustrated by the experiences of the Southern European economies in the 90's. For instance, such an effect would be of tremendous importance for a country like Greece in which inflation turned out to be higher than in most European countries and in which central bank credibility is thought to be low. The second reason lies on a legal basis: future admission in the EMU may be conditional on the fulfillment of several criteria, including a period of stability of the currency against the Euro. Such a requirement was at the source of the idea of the "EMS BIS", a system of monetary cooperation between the European Central Bank (ECB) and the central banks of non-member countries willing to join EMU in the near future.

Credibility of the monetary policy is an important feature of an exchange rate peg, as in the EMS. As reported by several authors like De Grauwe (1996) such a feature is not accounted for by the traditional OCA analysis. ${ }^{4}$ This is an important point against the OCA approach, since credibility considerations imply that the use of the exchange rate is costly. The recent theoretical literature ${ }^{5}$ has nevertheless attempted to include this dimension in general equilibrium models (see for instance Ricci 1997). However, as implied by the traditional OCA approach, the empirical literature that heavily relies on the characterization of the degree of asymmetry of shocks (which is the implicit but central criterion of the identification of an OCA) does not account for credibility. Compared to a flexible exchange rate, credibility issues affect the willingness of governments to use the exchange rate as a stabilization tool. Therefore, empirical measures based on asymmetric shocks or cycle desynchronisation have to be adjusted if one aims at assessing the effective stabilization cost of going from the EMS (or EMS-bis) to EMU. This is thought to lead to a more accurate assessment of the stabilization cost of moving from the EMS (or EMS-bis) to EMU. The aim of this paper consists of addressing this issue. Here, we assume that credibility of the monetary policy may be undermined if the pressure to se the exchange rate as a stabilization instrument is relatively high. In turn, this incentive is related to the fact that there

${ }^{4}$ This induces the development of what De Grauwe (1996) calls the "New Theory of Monetary Integration".

${ }^{5}$ For a recent survey, see Lafrance and St-Amand (1999). 
is a severe desynchronisation of the business cycles. ${ }^{6}$

It is also worth pointing out that the subsequent OCA analysis can also be useful for assessing the problems of conducting a single monetary policy in the Current EMU. The recent experience of the European Central Bank shows that desynchronisation of business cycles makes the timing of the change in interest rates quite difficult. ${ }^{7}$ Indeed, the recent hike in the interest rates of the main refinancing operations undergone by the ECB in early November 1999 has been considered quite differently by EMU members: for some countries that seem to face the expansionary phase of the cycle (like Spain or the Netherlands) it came too late and was perhaps too limited in its magnitude ${ }^{8}$; for other countries still facing adverse economic conditions like Germany or Italy, it came perhaps too early. Finally, for intermediate countries like Belgium and France, the timing was considered optimal. This recent experience suggests that the emphasis on desynchronisation put by the OCA approach is still relevant to gauging the efficiency of some policy instruments including monetary policy.

In order to adjust the empirical measures of cycle (de)synchronization and to define what is a severe desynchronisation, we first make a distinction between the various phases of the business cycle. Such an analysis is performed through the estimation of a multivariate Markov-switching model that explicitly characterizes the various regimes. The cycle desynchronisation measures rely on the (smoothed) probability of being in a particular regime. The idea of our approach is that the authorities of a particular economy will rely on exchange rate adjustment (at the cost of losing the credibility of its monetary policy) only if the potential stabilization is high. Said equivalently, the exchange rate will be adjusted only if the country faces an idiosyncratic situation. This leads us to give more weight in the computation of the empirical measures when the pair of countries face diverging cycle phases. Different desynchronisation measures are proposed and lead us to conclude that the first stage EMU is closer to an OCA than suggested by the

\footnotetext{
${ }^{6}$ It should be obvious that per se, the Markov-Switching methodology is not able to account by the restrictions put by credibility considerations in the use of nominal exchange rates. Nevertheless, we assume that these considerations increase the threshold of desynchronisation above which the net gain of using the exchange rate becomes positive.

${ }^{7}$ This problem is different from the issue related to the discrepancies in the transmission of monetary policy across EMU members.

${ }^{8}$ In late April, the Spanish government took a set of measures to cut off some controlled prices like energy in order to curb inflation.

${ }^{9}$ As far as we know, only one similar approach to ours has simultaneously been developed by Artis, Krolzig and Toro (1999).
} 
previous literature. By contrast, they confirm that some non-members like the UK or Norway face some idiosyncratic business cycles.

The paper is organized as follows. Section 2 reminds the empirical literature on asymmetric shocks and motivates our approach through some stylized facts. Section 3 presents the methodology. Section 4 reports the results and section 5 concludes.

\section{Measuring Asymmetric Shocks}

\section{A. Existing Literature}

Most of the empirical applications of the OCA theory rely on the criterion of asymmetric shocks or cycle desynchronisation. Basically, the reason is that the traditional stabilization channels emphasized in the literature turn out to be of limited scope in the European case: the degree of international labor mobility is very low (Obstfeld and Peri 1998), wage flexibility is limited (Bean 1999) and fiscal federalism with stabilization purposes remains unrealistic without deeper political integration. As a result, the extent of cycle desynchronisation provides a good criterion for assessing future potential stabilization costs.

Table 1 provides a (not necessarily representative) sample of the empirical analysis of asymmetric shocks.

Several comments are in order. The first striking feature is that these analyses

Table 1. Optimal Composition on EMU and Shocks Asymmetry

\begin{tabular}{|c|c|c|c|}
\hline Paper & Method & Approach & Core \\
\hline von Hagen and Neumann (1994) & $\begin{array}{l}\text { Real exchange rate } \\
\text { variability }\end{array}$ & bivariate & $\mathrm{Ge}, \mathrm{Au}, \mathrm{Be}, \mathrm{Nl}$ \\
\hline DeSerres and Lalonde (1995) & $\begin{array}{l}\text { Real exchange rate } \\
\text { variability }\end{array}$ & bivariate & $\mathrm{Ge}, \mathrm{Be}, \mathrm{Nl}$ \\
\hline Helg and et al. (1995) & $\begin{array}{c}\text { Sectoral Analysis/ } \\
\text { VAR }\end{array}$ & bivariate & $\mathrm{Ge}, \mathrm{Be}, \mathrm{Nl}, \mathrm{Dk}, \mathrm{Fr}, \mathrm{UK}$ \\
\hline $\begin{array}{l}\text { Bayoumi and Eichengreen } \\
\text { (1993) }\end{array}$ & Structural VAR & bivariate & $\mathrm{Ge}, \mathrm{Be}, \mathrm{Nl}, \mathrm{Dk}, \mathrm{Fr}$ \\
\hline Artis and Zhang (1995) & $\begin{array}{c}\text { Cyclical } \\
\text { Compounds } \\
\text { Identification }\end{array}$ & bivariate & $\mathrm{Ge}, \mathrm{Be}, \mathrm{Fr}, \mathrm{Nl}, \mathrm{Sp}, \mathrm{Pr}$, It \\
\hline Beine and Hecq (1997) & $\begin{array}{c}\text { Codependence in } \\
\text { VMA }\end{array}$ & bivariate & $\mathrm{Ge}, \mathrm{Be}, \mathrm{Nl}$ \\
\hline Rubin and Thygesen (1996) & $\begin{array}{c}\text { Codependence in } \\
\text { VAR }\end{array}$ & multivariate & $\mathrm{Ge}, \mathrm{Fr}, \mathrm{Be}, \mathrm{Nl}, \mathrm{Dk}, \mathrm{Fi}$ \\
\hline
\end{tabular}


rely on quite different methodologies, although the structural VAR approach seems to constitute "a mainstream". Nevertheless, it is worth mentioning that in no case is a particular weighting scheme adopted to account for the credibility issue. In other terms, the implicit hypothesis is that any slight divergence in the cycles can induce a change in the exchange rate without any credibility cost. Our basic argument is that such an assumption is correct in a flexible exchange rate system but not in a fixed and adjustable exchange rate system like the EMS. Some stylized facts are recalled next to stress this point. The second point is that most of the studies (except Rubin and Thygessen 1996) conclude in favour of a two-speed Europe. Put differently, EMU is not an OCA since there is a clear-cut distinction between a core and a periphery. Since credibility considerations restrict the use of exchange rates as stabilization instruments, it is however expected that our measures may lead to a different conclusion.

\section{B. Some Stylized Facts About the Use of Exchange Rate}

In many European countries, monetary authorities (we make no distinction here between the government and the central bank) decided to take part of the EMS in order to "borrow" the credibility of the so-called "hard currency" countries like Germany. This is obviously the case of Southern countries like Italy or Spain in order to foster inflation convergence. This was also the case of Belgium whose experience is quite interesting. As documented by De Grauwe (1994), Belgium decided to devalue the Belgium Franc in February 1982 against the other EMS currencies because it faced a hard and atypical recession in Europe. In this case, the stabilization gain was thought to outweigh the loss of credibility of monetary policy (which was translated after wars into a risk premium vis a vis German interest rates). After 1985, things completely changed. The huge public debt induced a priority on low interest rates. The strategy adopted then was to restrict the use of exchange rate changes (i.e. realignments) even in face of small diverging performances with respect to Germany (as in 1990 for the reunification shock) in order to speed-up interest rate convergence.

Such a story holds for other countries as well. To illustrate this point, let us also consider the case of France and the Netherlands. We combine information concerning the evolution of industrial production since 1979 and the dates of realignments with respect to the Deutsche mark (DM). Figures 1 and 2 present a seven months centered moving average of the rates of growth of industrial production thought to capture (crudely) the national business cycles. The growth 
rates are computed as the 12-month percentage change of production. Each figure compares the German situation (denoted $\mathrm{grm}$ ) with that of a given country. Industrial production series are drawn from OECD tapes. The dates of realignment with respect to the DM (noted rea) are indicated by bold vertical lines.

In France the last realignment occurred in 1986. It followed a period of obviously divergent business cycles between France and Germany. Between 1989 and 1992 the French industrial production growth rate $(\mathrm{frm})$ slowed down in comparison with the German one. Despite this divergent evolution of business cycles, realignments of the French franc did not take place. For the Netherlands, which had engaged in a pegging strategy of the Guilder to the Mark since the early eighties, credibility can be considered as a still more important aspect given its small size and high openness. The Dutch industrial production growth rate $(\mathrm{nlm})$ was much more volatile than the German one between 1986 and 1988. It was also by far lower in many instances. Nevertheless, this did not lead to realignment. More interesting is the fact that the same phenomenon as in France (although less pronounced) occurred between 1990 and 1992 in the Netherlands. The Dutch industrial production experienced a slow down in its growth rate in comparison with the German one but the Netherlands maintained the exchange rate pegging strategy.

To sum up, the analysis of the experiences of France and the Netherlands experiences with exchange rate management during the eighties clearly shows that they sought to maintain the evolution of their DM exchange rate within the band of fluctuations despite some slight divergence between their business cycle and the German one. Such a behavior is more noticeable when we consider the 1987-1992 period during which the credibility of the ERM has become an important and wellestablished objective. Combined with the Belgian experience, it suggests that the use of exchange rate as a stabilization instrument is much more complex that the one suggested by the pure OCA theory: government will use it only they face a idiosyncratic and lasting recession; by contrast, they will be reluctant to rely on such an instrument if the cycle phases are similar although not completely correlated.

\section{The Methodology}

To conduct our empirical analysis of cycle desynchronisation, we proceed in two steps. In a first stage, we estimate the business cycle for each country through a multivariate Markov Switching model (Hamilton 1994 and Warne 1996) including a real variable and a nominal one. While rather new in a multivariate 
setting $^{9}$, the phases of the business cycle have been extensively and consistently captured by the regimes identified by Markov Switching models (inter alii). The choice of a multivariate model comes from the fact that univariate analyses ${ }^{10}$ of the business cycle (see Table 1) (usually based on GDP or industrial production) turn out to be restrictive: the cycle, as traditionally defined by Burns and Mitchell (1946), should summarize the information contained in an exhaustive set of variables. The business cycle characterization can be thus misleading if both a nominal and a real variable are not included ${ }^{11}$. Furthermore, our approach share the same variables as some of the "single-regime" approach reported in Table 1, like the well-known one of Bayoumi and Eichengreen (1993), which is convenient for comparison purposes. The estimation of the Markov Switching model provides conditional probabilities of being in one particular state, which can be interpreted as a phase of the business cycle (recession or expansion). Of course, regimeindependent approaches are unable to explicitly characterize the position of the economy in terms of regime. Another advantage of such an approach is that the characterization of the business cycle does not require any expert judgment, as is the case for the NBER dating procedures. Here, inflation represents the nominal variable and unemployment the real variable. While differing from Artis, Krolzig and Toro (1999) who consider industrial production, unemployment rates convey the advantage of being directly comparable across countries (we use the Standardized Rates of Unemployment issued by OECD). In the second stage, from this business cycle characterization, we develop several non-parametric indicators of synchronization. These indicators can be adjusted to include the restrictive use of exchange rates implied by the fixed exchange rate system.

\section{A. Markov Switching VAR Analysis}

Let $x_{t}$ be a bivariate time series with components $x_{t}=\left(\Delta u_{t}, \Delta p_{t}\right)$, where $\Delta u_{t}$ and $\Delta p_{t}$ are the quarter-to-quarter changes in respectively the unemployment rate and the consumer price level. Since $\Delta u_{t}$ and $\Delta p_{t}$-which seem to be integrated of order 1 over the whole period under investigation ${ }^{12}$ - are not cointegrated, the vector $x_{t}$ is assumed to be well characterized by the following general Markov Switching $\operatorname{VAR}(p)$ model:

\footnotetext{
${ }^{10}$ See for Example Hamilton (1989).

${ }^{11}$ One exception is Ballabriga et al. (1999) who studied output and inflation. The two variables are however treated separately, which may influence the identification of the cycles.

${ }^{12}$ See section 3.1 for more details on the stationarity properties of inflation and unemployment over the investigated period. The results of the test are reported in Appendix 1.
} 


$$
x_{t}=\mu_{s_{t}}+\sum_{k=1}^{p} A_{s_{t}}^{k} x_{t-k}+\varepsilon_{t}, \quad t=1,2 \ldots, T
$$

where $p$ denotes the VAR order, $\varepsilon_{t} \mid s_{t} \sim N\left(0, \Omega_{s t}\right)$ with $\Omega_{s_{t}}$ the covariance matrix being positive definite. The special insight given by the Markov Switching (MS) approach is the use of an unobserved or regime variable $s_{t}$ which is assumed to follow a $q$-state Markov process with transition probabilities $\operatorname{Pr}\left(s_{\tau}=j \mid s_{t-1}=i\right)=p_{i j}$, for all $t$ and $i, j=1,2, \ldots, q$, with $\sum_{j=1}^{q} p_{i j}=1$. The Markov process is assumed to be irreducible (no absorbing states) and ergodic.

Throughout the whole analysis, we will assume that $q=2$, i.e. that two regimes are sufficient to characterize the joint dynamics of changes in unemployment and inflation. ${ }^{13}$ Typically, these may be referred to an expansionary and a recessionary regime. Given the short sample, we will constraint $p \leq 4$. In this general specification, the random vector $\mu_{s_{t}}$, the random matrices $A_{s_{t}}^{k}$ and the covariance matrix $\Omega_{s_{t}}$ are allowed to depend on the regime variable $s_{t}$. Nevertheless, in order to use a parsimonious framework, we also allow for a restricted model in Wwhich $\Omega_{s_{t}}$ is the same across the two regimes, i.e. that the volatility of the joint process is the same during booms and busts. In the constrained case, we will refer to model $m=2$ while in the general case, we will refer to model $m=1$.

Maximum likelihood (ML) estimates of model (1) are obtained via the wellknown Expectation Maximum Likelihood-algorithm (see for more details Hamilton, 1994). The underlying distribution in the ML estimation procedure is assumed to be Gaussian. Our model selection procedure with respect to $m$ and $p$ will be based on the two following sets of statistics. The first one is the well-known set of information criteria (Akaike, Schwarz Bayesian Criterion) that are used to select the VAR order $p$. The second one will refer to misspecification tests that allow an assessment of the goodness-of-fit properties of the various estimated models. Three specification tests -all based on the conditional scores- are applied both to each equation and to the full system. The first one is an autocorrelation test that

\footnotetext{
${ }^{13}$ Basically, this choice relies on two arguments. From a purely statistical point of view, there does not exist (to the best of our knowledge) any statistical test aiming at assessing the presence of a third regime. As a second best, we have estimated the models with $q=3$ and notice in most cases only moderate increases in the log-likelihood values (the results are available upon request). From an economic point of view, the interpretation of the third regime turns out to be cumbersome as well as an asymmetric characterisation (for instance two expansionary regimes and only one recessionary state). In the context of our analysis, one may argue that the difference between two expansionary regimes is irrelevant and does not matter for assessing the magnitude of the stabilization cost.
} 
examines whether the conditional scores with respect to at $\mu_{i}$ time $t$ are correlated with the conditional scores with respect to $\mu_{j}$ at time $t-1$. The second one is an ARCH-type test that compares the conditional scores at time $t$ with respect to the unique element of $\Omega_{i}$ with the conditional scores at time $t-1$ with respect to the unique element of $\Omega_{j}$. Finally, we rely on a test investigating the Markov chain assumption along the lines defined by Hamilton (1991). This test compares the conditional scores at time $t$ with respect to $p_{i i}$ with the conditional scores at time $t-1$ with respect to $p_{i i}$ and $\mu_{i \cdot}{ }^{14}$ All selected models are required to both satisfy one of the information criteria and to pass the misspecification tests.

Once model (1) estimated, it is possible to recover for all $t$ the implied probability that the economy $k$ is in state $1\left(P_{k}\left(s_{t}=1\right)\right)$ that turns out to be the recessionary regime in our analysis. In the terminology of Markov-switching models, these probabilities are called smoothed probabilities because they use all the information available up to $t=T{ }^{15}$ Our subsequent assessment of desynchronisation of business cycles is then based on the sequence of these probabilities. Thus, by contrast to NBER methods, our cycle dating is fully data driven. Next section exposes the building of desynchronisation indexes.

\section{B. Indicators of Desynchronisation}

Indicators of desynchronisation help us to assess how coincident are the phases of the business cycle among a set of countries. If two countries share at the same time an expansion or a recession, they can be considered as highly synchronized and so, for instance, constitute an optimal currency area without the need to search for any specific additional stabilization tool. Therefore, in our MS-VAR framework, a straightforward way to gauge the degree of synchronization between two countries simply consists in comparing the (smoothed) probabilities of being in a particular regime (recession or expansion). If the (absolute) difference is low, then countries are synchronized, otherwise they are desynchronized. For each pair of countries $k$ and $l$, denoting $P_{k}\left(s_{t}=1 / I_{T}\right)$ as the probability of country $k$ being in regime 1 at time $t$ (on the basis of all available information) the indicator can be written as follows over the sample $\{1 \ldots T\}$ :

\footnotetext{
${ }^{14}$ See for more details Hamilton (1991).

${ }^{15} \mathrm{By}$ contrast, the computation of the filtered probabilities rely on the information set available up to $t=t$. ${ }^{16}$ Another reason is that a lower value of $I_{1}$ may simply reflect a slight difference in the estimation of the respective models.
} 


$$
I_{1}=1-\frac{\sum_{t=1}^{T}\left|P_{k}\left(s_{t}=1 / I_{T}\right)-P_{l}\left(s_{t}=1 / I_{T}\right)\right|}{T}
$$

In (2), we consider 1 minus the difference in order to get a positive relationship between the indicator and the degree of synchronization.

This $I_{1}$ indicator does not however make use of the distinction between cycle phases. To this extent, it is in line with the analysis of the previous literature relying on "raw" correlations. It must therefore be considered here as a benchmark for comparison purposes with the subsequent indicators. As exposed in section 2, what matters for assessing the loss of exchange rate, as a policy instrument is rather the relative position of each country in the business cycle. Two countries can share the same phase of the business cycle, without necessarily displaying similar conditional probabilities. In this last case, credibility considerations would obviously imply a stability of their bilateral exchange rate. ${ }^{16}$ In this view, we propose another indicator that computes the part of the sample during which two countries share the same phase of the cycle. This indicator is based on a binomic variable $I_{b, t}$, which takes the 1 value if the both countries share the same phase of the business cycle (both in expansion, both in recession or neither in recession nor in expansion) and the 0 value if they do not share the same phase of the business cycle. To build this indicator it is necessary to characterize business cycle expansion and recession from our bivariate probabilistic model. Following Hamilton (1989), a recession (an expansion) is characterized by a conditional probability of being in state 1 over 0.7 (under 0.3$)$ : (resp. $P_{k}\left(s_{l}=1 / I_{T}\right)>0.7$ (resp. $P_{k}\left(s_{t}=1 /\right.$ $\left.\left.I_{T}\right)<0.3\right){ }^{17}$

Then, the $I_{2}$ indicator can be expressed as:

$$
I_{2}=\sum_{t=1}^{T} \frac{I_{b, t}}{T}
$$

The higher the indicator $I_{2}$, the higher is the proportion of periods in which both economies share the same cycle phase and the lower the use of the nominal exchange rate is required. However, this indicator may still appear too restrictive. Basically, given our thresholds, we have three situations: the two countries share the same phase, they are in opposite regimes and finally the criterion is inconclusive. As exposed in section 2, experiences of several countries suggest that the use

\footnotetext{
${ }^{17}$ The sensitivity of the results to the choice of these limit values $(0.7$ and 0.3$)$ has been performed and does not appear to modify significantly the results.
} 
of the exchange rate may be used only when a country faces a relatively isolated recession (or expansion). Therefore, we consider a third indicator that uses a different weight. The underlying indicative variable $\left(I_{c, t}\right)$ takes then a value of 0.5 when countries do not share an opposite phase (i.e. $I_{c, t}=0.5$ if $P_{k}\left(s_{t}=1 / I_{t}\right)>0.7$ and $0.3<P_{l}\left(s_{t}=1 / I_{t}\right)<0.7$ or if $P_{k}\left(s_{t}=1 / I_{t}\right)<0.3$ and $\left.0.3<P_{l}\left(s_{t}=1 / I_{t}\right)<0.7\right)$. In the other cases, the values of $I_{c, t}$ are the same as the ones taken by $I_{b, t}$ still holds. Hence, the $I_{3}$ indicator can be expressed as:

$$
I_{3}=\sum_{t=1}^{T} \frac{I_{c, t}}{T}
$$

To complete the analysis, we also need a measure of the duration of the synchronization between a set of countries. Indeed, Cohen and Wyplosz (1989) single out the persistence of divergence as equally important as the extent of divergence when comparing business cycles. Similarly, the need to conduct stabilization policies for instance through net fiscal transfers in a fiscal federalism system similar to the one prevailing in the United States or through discretionary domestic fiscal policies is rather limited if asymmetric shocks are of a very temporary type (say one quarter). To this aim, an additional indicator $\left(I_{4}\right)$ representing the average length of a synchronization period is also constructed from the $I_{2}$ indicator. If we denote the length of a period $i$ during which $I_{b, i}=1$, length ${ }_{b i}$, then $I_{4}$ has the following form:

$$
I_{4}=\sum_{i=1}^{n} \frac{\text { length }}{n}
$$

where $\mathrm{n}$ is the numbers of periods for which $I_{b, t}=1 .{ }^{18} \mathrm{~A}$ further advantage of the $I_{4}$ is that its value has a direct economic interpretation. The higher the indicator, the stronger is the synchronization between the business cycles of the two countries. A low value of $I_{4}$ associated with a higher value of the other indicators means that countries often share the same phase of the business cycle, but with frequent and short desynchronisation periods. By contrast, a high value of $I_{4}$ associated to a low level of the other indicators means that desynchronisation and synchronization periods are quite long and not erratic.

\footnotetext{
${ }^{18}$ This type of indicators have been extensively used in order to measure exchange rate misalignment (see Perée and Steinherr (1989) for instance).
} 


\section{Empirical Results}

\section{A. Data Issues}

In our analysis, we consider two variables, the (changes in) unemployment rate $(\Delta u)$ and consumer prices $(\Delta p)$ measured on a quarterly basis. The use of a quarterly frequency is justified by the need to observe cycles that are expected to be cushioned by a stabilizing fiscal policy or by an adjustment of the (effective) nominal exchange rate in the spirit of this study. In turn, the use of unemployment rather than GDP as a proxy for economic activity is justified by the nonavailability of reliable quarterly data over a sufficiently long period for an important set of countries. Furthermore, by contrast to quarterly GDP, unemployment data are harmonized across countries, which is crucial for comparison purposes.

All data come from the OECD-BSDB database. We consider 11 European countries including EMU participants (Germany, France, Italy, Spain, Finland, Portugal and the Netherlands) but also possible future candidates (Norway, the UK, Switzerland and Sweden). Because of the poor quality of their unemployment data, Belgium, Denmark, Portugal and Austria were dropped out from the sample. ${ }^{19}$ The period under investigation ranges from 1975Q1 to 1996Q4. This choice is made for three main reasons. The first one is related to the statistical properties of the data. Our MS VAR framework indeed requires the data to be $\mathrm{I}(0)$. For some sub-periods including the early 70's, prices have been be found to follow an I(2) process. In order to cope with this problem, along the lines proposed by Juselius (1994), we ignore this sub-period. The second reason lies in the need to consider a period homogeneous with respect to international monetary agreements. In this respect, it appeared advisable to consider a post-Bretton-Woods period in which the pegging of several exchange rates is exclusively due to European arrangements.

Before conducting the MS-VAR analysis in first differences, the stationarity of inflation and of the changes in unemployment should be tested To this aim, Appendix 1 presents the results of the two most popular unit root tests, the Augmented Dickey-Fuller (ADF) test (with three different lag order determination procedures) and the non parametric Phillips-Perron one. The latter may indeed

\footnotetext{
${ }^{19} \mathrm{~A}$ detailed inspection of the data reveals that most quarterly values have been interpolated from annual data. This is of course highly problematic in a business cycle analysis conducted on a quarterly basis. Data problems were also encountered for Denmark, Ireland and Greece.
} 
display more power than the ADF tests in small samples and in the presence of breaks. From Appendix 1, it comes out that in general, there is evidence in favour of a stationary inflation process over the 1975Q1-1996Q4 periods. For 7 out of 11 countries, inflation is clearly found to follow an $\mathrm{I}(0)$ process. For two countries (France and Norway), there is some moderate evidence in favour of a non stationary process but these results are not found quite robust. ${ }^{20}$ Finally, for Italy and Spain, inflation is found to follow a I(1) process, which is to some extent meaningful since these countries have undergone a continuous desinflation process over the investigated period. Nevertheless, it is well known (see for instance Dolado et al, 1993) that these unit root tests display poor power properties in finite samples. Given the number of data points $(T=88)$, the conclusions should be drawn with caution. ${ }^{21}$ Second, the stationarity of inflation is a usual starting point in the empirical analysis conducted over similar periods (see Juselius 1995 or Clarida, Gali and Gertler 1997 on this point). We will thus use the (raw) inflation data in our VAR analysis.

\section{B. Estimation Results}

For each country, the MS VAR models selected along the lines, exposed in section 2.1. are presented in Appendix $2 .^{22}$ Nearly all models are found to pass the misspecification tests at a 5\% nominal level. The transition probability matrices suggest that the estimated regimes are found to be sufficiently persistent, i.e. $P_{11}$ and $P_{22}$ are close to 1 , which ensures a meaningful decomposition in terms of cycle phases. In Figures (3a) and (3b) (Appendix 3), the estimated smoothed probabilities are plotted for each country.

From the evolution of the recession probabilities, it is possible to distinguish the major business cycles phases in each economy. Although with a different methodology, the results reproduce most of the major features emphasized in some of the previous studies. By contrast to a simple characterization of turning points, our probabilities provide the global shape of the cycle phases. However, this methodology does not directly yield any measure of cyclical amplitude. Such a limitation is not detrimental to our analysis since the emphasis is clearly put on synchronization. For the sake of illustration, Appendix 4 reminds of the most

\footnotetext{
${ }^{20}$ The test statistics of the $\mathrm{ADF}(\mathrm{BIC})$ and the Phillips-Perron tests are indeed rather close to their critical values. Furthermore, restricting the period leads to a change in the conclusions.

${ }^{21}$ Once more, for Italy, the acceptation levels are not very high.

${ }^{22}$ As stated before, Akaike or Schwarz Bayesian criteria are used to determine the lag structure.
} 
important turning points for the four major economies identified by Artis, Kontolemis and Osborn (1997). In the case of Germany, our implied cycle phases are consistent with the peaks in 79M12 and 86M5 as well as the troughs in $82 \mathrm{M} 10$ and $86 \mathrm{M} 12$. Moreover, the model captures the reunification shock, which has been affecting the German economy in 91Q1 and its consequences in terms of inflationary pressures and unemployment variations. For France, the following turning points are more or less reproduced: for the troughs, 77M10, 82M10, 85M2 and for the peaks 76M12, 79M9, 82M3, 84M2, 92M1 (with some lag). With respect to the UK, the probabilities are in lines with the detected troughs $(81 \mathrm{M} 2$, $84 \mathrm{M} 8,92 \mathrm{M} 4)$ and with the peaks $(79 \mathrm{M} 4)$. In the Italian case, the identified peaks in $80 \mathrm{M} 3,89 \mathrm{M} 12$ and troughs in $77 \mathrm{M} 12$ and $83 \mathrm{M} 3$ are also well captured. The reproduction of these stylized facts justifies the choice of a MS VAR representation to characterize economic fluctuations from which asymmetric shocks are inferred. ${ }^{23}$

Appendix 5 provides the results in terms of desynchronisation indicators. Rather than resorting to a set of bivariate analysis with a chosen reference country (usually chosen as Germany), it is better to determine an OCA or to assess the stabilization costs of a geographic zone in a multivariate way, as pointed out by De Grauwe (1996). This strategy has been followed by several authors like Bayoumi and Eichengreen (1997), Rubin and Thygesen (1997) or Beine, Candelon and Hecq (2000). One obvious reason is that an OCA is a multi-country concept and its determination is made through multivariate bargaining. For instance, France may be willing to support Spain's adhesion because of strongly synchronized business cycles even though the correlation between Italy and Germany is relatively low (this is purely a hypothesis). Therefore, our results are provided in terms of a complete set of cross-country correlations computed for the three desynchronisation indicators.

For each indicator, the use of a threshold value may be useful in order to assess the need of stabilization policies. Of course, the choice of a specific value is somewhat arbitrary but some robustness analysis may be easily carried out. Since the indicators are different from each other, it is natural to use different thresholds. As a matter of choice, we use the following values: 0.6 for $I_{1}$ and $I_{3}$, and 0.5 for $I_{2}$

\footnotetext{
${ }^{23}$ Of course, there is some discrepancy between some turning points reported in Table 3 and the regimes identified in this paper. The differences may be explained by several factors. First, our system involves unemployment rates rather than GDP (unemployment often lags GDP fluctuations). Second, the VAR includes inflation in contrast with Artis et al. (1997). Finally, our regime makes reference to cycle phases rather to turning points.
} 
that turns out to be more restrictive. By contrast, since the $I_{4}$ indicator has a straightforward interpretation, i.e. the average number of periods where business cycles are synchronized, the choice of a specific threshold is much easier. In this respect, an average period of synchronization of one year, i.e. 4 periods, seems rather reasonable.

The first indicator $I_{1}$ reveals three different groups with respect to their correlations with the remaining countries under investigation. The first one includes countries, which are found to be highly correlated either with each other or with other EMU members. ${ }^{24}$ These are Germany and Italy (with respectively 6 and 7 values above the threshold) as well as Finland ${ }^{25}$ and Portugal. In addition, an intermediate group emerges, including France ${ }^{26}$, the UK and the Netherlands, which are found to display similar cycles with the first group and especially Germany. In this respect, the exclusion of the Netherlands from the first group may be due to the recent divergent performance of this country in terms of unemployment. Indeed, over the recent period, the situation of the labor market in the Netherlands has significantly improved while the other European members faced worsening conditions. This recent divergence is reflected in Figure (3a) by the low conditional probability of being in the recessionary regime around 1995. Finally, the analysis of the values of $I_{1}$ suggests the existence of a third group including countries with rather idiosyncratic cycles. ${ }^{27}$ These are Spain, Norway, Switzerland, and Sweden. As a whole, these results can be considered more or less in line with the findings of the empirical OCA literature. ${ }^{28}$ Therefore, the $I_{1}$ indicator, which does not take account of cycle phases, is, as expected, very in line with single-regime models based indicators of occurrence of asymmetric shocks.

The introduction of credibility issues through the characterization of cycle phases is expected to give a more optimistic picture of the actual EMU. Indeed, credibility amounts to a restriction of the use of the exchange rate and thus the stabilization cost induced to its loss. To a certain extent, this is confirmed by the

\footnotetext{
${ }^{24}$ This group is often referred to as the "core" in the OCA literature.

${ }^{25}$ The inclusion of Finland may sound counter-intuitive but this result is also found by Rubin and Thygessen (1997).

${ }^{26}$ The exclusion of France of the core is also well documented by some other OCA studies like Bayoumi and Eichengreen (1997).

${ }^{27}$ Similarly, this group is often referred to as the "periphery".

${ }^{28}$ For recent surveys, see for instance Buti and Sapir (1998) or St-Amand and Lafrance (1999). Most empirical OCA studies conclude in favor of a core-periphery distinction. Nevertheless, it comes out that there is a deep disagreement across the main studies on the precise composition of the respective groups, as suggested by Table 1 .
} 
inspection of the $I_{2}$ indicator. It may be seen that for instance the Netherlands but also Spain are found on the basis of this measure to have more synchronized cycles with their European partners. In turn, this leads to an extension of the socalled core group. By contrast, the UK is found to be much less synchronized than implied by the first indicator. This suggests that for this country, the peaks and troughs of the business cycles occur at relatively different times compared to the European continental countries, which is in line with previous findings (Artis and Zhang 1997 and 1999 for instance). The periphery implied by this indicator would contain the UK, Sweden and to a lesser extent Switzerland and Norway. ${ }^{29}$

The use of the indicator $\mathrm{I}_{3}$ leads to quite a similar picture, with nevertheless a more pessimistic assessment for Spain. ${ }^{30}$ Nevertheless, while inferior to our chosen threshold, the values for Spain are higher than those obtained for the countries that were found to belong to the periphery, i.e. the UK, Switzerland, Sweden and Norway. The computation of this indicator thus confirms the main conclusions of the $I_{2}$ indicator, with the Netherlands displaying a synchronized cycle and the UK a more idiosyncratic one. Thus, the $I_{3}$ indicator suggests that our findings are robust to the specific choice of threshold values. In general, it is found that accounting for the turning points of the business cycles $\left(I_{2}\right.$ and $I_{3}$ indicators) can lead to different results with respect to more classical indicators represented here by $I_{1}$.

The $I_{4}$ indicator turns out to shed an interesting light on the synchronization patterns of the European countries. Countries like France, the Netherlands or Spain, which appeared to be less synchronized on the basis of the previous indicators display in fact rather long periods of synchronization. It is found that on average, these countries share the same cycle phase with Germany at least for a period longer than five quarters. To a certain extent, the same applies for Switzerland. By contrast, countries like Norway, Sweden or the UK face rather short periods of synchronization. Combined with the evidence provided by the previous indicators, this means that these countries display idiosyncratic dynamics and could face rather high stabilization costs if they were deprived of the traditional monetary stabilization instruments.

An homogeneous picture emerges from this non parametric analysis: there is a

\footnotetext{
${ }^{29}$ For these two countries, note that 2 out of the 3 positive occurrences are just above the threshold value (0.5).

${ }^{30}$ It is worth reminding that compared to $I_{2}$, the $I_{3}$ indicator allocates less weight to different but contiguous cycle phases.
} 
core of countries with synchronized business cycles including Germany, Italy, Finland, Portugal and to a lesser extent the Netherlands; an intermediate group facing higher potential stabilization costs composed of France and Spain which could find it useful to rely for instance on domestic fiscal policies and finally, a peripheral group of economies facing more idiosyncratic dynamics including the UK, Norway, Switzerland and Sweden. Interestingly enough, the two first groups are made up of countries belonging to the first stage EMU and the last one includes non-members. This could suggest that the current EMU could work reasonably well without resorting too often to the provisions of the Stability Pact. By contrast, a prospective enlargement of the monetary union aiming at including for instance Sweden, the UK or Norway could be considered with caution. To a certain extent, the here-obtained OCA measures suggest that the current positions of these countries with respect to EMU are rational. If these countries were to consider membership of the EMU, they should ensure that alternative measures aiming at stabilize national economies will be available.

\section{Conclusion}

In this paper, we have proposed an OCA-related analysis for most European countries including future potential adherents to EMU. In line with the empirical literature, we have focused on the issue of cyclical desynchronisation. Nevertheless, by contrast to the previous literature, we rely on a Markov Switching VAR approach that characterizes the business cycle phases, in order to account for the restrictions put by credibility considerations on the use of nominal exchange rates. The importance of the credibility issue stems from the fact that the alternative to EMU was and will be a fixed but adjustable exchange rate system, namely the EMS and the EMS2.

In this perspective, we propose a set of non-parametric indicators based on the conditional probabilities of being in a particular regime implied by the MS VAR. The results suggest that this strategy leads to a more optimistic picture for the new EMU than those proposed by the other empirical analyses that neglect the position of the economy in their business cycle. In particular, this suggests that the present EMU countries will not face too many problems in losing flexibility in their intraEuropean nominal exchange rates and that few economies will have to rely on the "escape clause" provisions of the stability pact. By contrast, some (so far) excluded countries like the UK or Norway could face important stabilization costs 
if joining the EMU without any alternative effective stabilization tool.

The approach based on the switching regimes VAR models deserves further developments. Among these, the setting up of a new desynchronisation indicator (based on a rank analysis for instance) reflecting the lags of the turning points between countries could be useful (although the practical implementation may turn to be computationally difficult). Although cumbersome, an inferential procedure testing for the null hypothesis of (de)synchronization would also be a valuable development of this approach.

\section{Acknowledgement}

The authors are grateful to A. Hecq, H.Lutkepohl and A. Sapir for wise comments as well as A.Warne for providing his programs. We also benefit from comments of the audiences at the ESEM'99 annual congress in Santiago de Compostella, at the 1999 conference on European Integration at the University of Lille II and at the annual workshop of Humboldt University at Helenenau. Bertrand Candelon acknowledges the financial support of the European TMR grant ERBFMRXCT-980213. The usual disclaimers apply.

Received July 2001, Accepted January 2002

\section{References}

Artis, M. and W. Zhang (1997), "International Business Cycles and the ERM: Is There a European Business Cycle?", International Journal of Finance and Economic, 2, pp.116.

Artis, M. and W. Zhang (1999), "Further Evidence on the International Business Cycles and the ERM: Is There a European Business Cycle ?", Oxford Economic Papers, 51, pp.120-132.

Artis, M.J., Z.G. Kontolemis and D.R. Osborn (1997), "Business Cycles for G7 and European Countries", The Journal of Business, 70(2), April, pp. 217-249.

Artis, M.J., H-M. Krolzig and J. Toro (1999), "The European Business Cycle", CEPR Discussion Papers, n.2242.

Backus, D.K. and P.J. Kehoe (1993), International Evidence of the Historical Properties of Business Cycles, American Economic Review, 82(4), pp. 864-88.

Ballabriga, F., M. Sebastien and J. Vales (1999), European Asymmetries, Journal of International Economics, 48(2), pp. 233-253.

Banerjee, A., J. Dolado, J. Galbraith and D. Hendry (1993), Co-Integration, Error 
Correction, and the Econometric Analysis of Non-Stationary Data, Oxford University Press, Oxford.

Bayoumi, T. (1994), “A Formal Model of Optimum Currency Areas”, IMF Staff Papers, 41, pp.345-367.

Bayoumi, T. and B. Eichengreen (1993), "Shocking Aspects of European Monetary Unification", in F. Torres and G. Giavazzi (eds), "Adjustment and Growth in the European Monetary Union", pp. 193-221.

Bayoumi, T. and B. Eichengreen (1997), "Ever closer to Heaven : An OCA Index for European Countries", European Economic Review,41, pp.761-770.

Beine, M., B. Candelon and A. Hecq (2000), "Assessing a Perfect European Optimum Currency Area: a Common Cycles Approach”, Empirica, 27, pp.115-132.

Beine, M. and F. Docquier (1998), "A Stochastic Simulation Model of an Optimum Currency Area", Open Economies Review, 9(3), pp. 227-255.

Blanchard, O. and D. Quah (1989), "The Dynamic Effects of Demand and Supply Disturbances", American Economic Review, 79, pp. 655-673.

Burns, A.F. and A.C. Mitchell (1946), "Measuring Business Cycles", NBER Press.

Buti. and A. Sapir (1998), Economic Policy in EMU, Clarendon Press, Oxford

Candelon, B. and P.Y. Henin (1995), "La récession des années quatre-vingt dix a-t-elle été exceptionnelle ?", Economie et Prévision,120, 1995-4 pp. 51-71.

Christodoulakis, N., S. Dimelis and T. Kollintzas (1995), Comparisons of Business Cycles in the EC: Idiosyncracies and Similarities, Economica,62, pp. 1-17

Clarida, R., J. Gali and M. Gertler (1997), "Monetary Policy Rule in Practice: Some International Evidence, CEPR Discussion paper n.1750.

Cohen, M. and C. Wyplosz (1989), The European Monetary Union: an Agnostic Evaluation, CEPR Discussion Paper n.306.

De Grauwe, P. (1994), “The Economics of Monetary Integration”, Oxford University Press, Oxford.

De Grauwe, P. (1996), “The Prospects of a Mini Currency Union in 1999”, CEPR Discussion Paper n.1458, September.

Ghironi, F. and F. Giavazzi (1999), Currency Areas, International Monetary Regimes, and the Employment-Inflation Tradeoff, Journal of International Economics,45, pp. 259296.

Hassler J., P. Lundvik, T. Person and P. Soderlind (1994), "The Swedish Business Cycle: Stylized Facts over 130 years" in "Measuring and Interpreting Business Cycles", Clarendon Press, Oxford, pp. 1-10. Swoboda, eds, "Monetary Problems in the International Economy", Chicago, University of Chicago Press.

Hamilton, P. (1989), "A New Approach to the Economic Analysis of Nonstationary Time Series and the Business Cycle", Econometrica, 2(2), pp. 357-384.

Hamilton, P. (1994), "Times Series Analysis" Princeton University Press.

Helg, R., P. Manassa, T. Monacelli and R. Rovelli (1995), How Much (a)symmetry in Europe ? Evidence from Industrial Sectors, European Economic Review, 39, pp. 10171041. 
Juselius, K. (1994), On the Duality Between Long Run relations and Common Trends in the I(1) versus the I(2) Model, Econometric Review,13, 151-179.

Karras, P. (1994), Aggregate Demand and Supply Shocks in Europe: 1860-1987, Journal of European Economic History, 22(1), pp. 79-98.

Kenen, P. (1969), "The Theory of Optimum Currency Areas : an Eclectic View", in R. Mundell and A. Swobada (Eds), Monetary problems in the International Economy, Chicago University Press, Chicago.

Mc Kinnon, R. (1963), "Optimum Currency Areas", American Economic Review, September, pp. 657-665.

Mundell, R. (1961), "A Theory of Optimum Currency Areas", American Economic Review, 51, pp. 715-725.

Obstfeld, M. and G. Peri (1998), "Regional Nonadjustment and Fiscal Policy: Lessons for EMU”, NBER Working paper n.6431.

OECD. (1999a), Country analysis: Denmark 1999, OECD Economic Studies n.3.

OECD (1999b), Country analysis: Sweden 1999, OECD Economic Studies n.18.

OECD (1999c), Country analysis: Norway 1999, OECD Economic Studies n.8.

Péree, E. and A. Steinherr (1989), "Exchange Rate Uncertainty and Foreign Trade", European Economic Review, 33, pp. 1241-1264.

Ricci, L.A. (1997), "A Simple Model of an Optimum Currency Area", Economie et Prévisions, 128, pp. 1-20.

Rubin, J. and N. Thygesen (1996), "Monetary Union and the Outsiders: a CointegrationCodependence Analysis of Business Cycles in Europe", in Economie Appliquée, tome XLIX, n.3, pp. 123-171.

Sachs, J. and X. Sala-I-Martin (1992), "Fiscal Federalism and Optimum Currency Areas: Evidence for Europe from the United States", CEPR Discussion Paper, n. 632, March.

Tavlas G. (1993), "The new Theory of Optimum Currency Areas", The World Economy, (16), pp. 663-685.

Warne A. (1996), "Causality in a Markov Switching VAR", Manuscript, Institute for International Economic Studies, Stockholm University. 
EMU Membership and Business Cycle Phases in Europe: Markov-Switching VAR Analysis 235

\section{Appendix 1. Unit Root Tests}

\section{A. Inflation}

\begin{tabular}{|lllll|}
\hline & ADF(BIC) & ADF(AIC) & ADF(LM) & PP(4) \\
\hline Por & $-6.48^{* *}$ & $-0.90^{*}$ & -0.63 & $-7.23 * * *$ \\
Swe & $-10.70^{* * *}$ & $-10.70^{* * *}$ & $-10.70^{* * *}$ & $-10.36 * * *$ \\
Fin & $-8.59 * * *$ & $-8.59 * * *$ & $-2.89 * *$ & $-6.13 * * *$ \\
N1 & $-5.34 * * *$ & $-2.74 *$ & $-5.34 * * *$ & -5.53 \\
Ita & -2.01 & -0.69 & -2.01 & -1.71 \\
Spa & -1.23 & -1.23 & -1.10 & -1.66 \\
Sui & $-8.47 * * *$ & -2.15 & $-9.27 * * *$ & $-8.71 * * *$ \\
Uk & $-4.04 * * *$ & $-4.04 * * *$ & $-3.71 * * *$ & $-4.39 * * *$ \\
Ger & $-3.47 * *$ & -2.25 & $-6.61 * * *$ & $-7.00^{* * *}$ \\
Nw & -2.03 & -1.44 & -2.03 & -2.52 \\
Fra & $-2.75 *$ & $-2.75 *$ & -1.12 & -2.46 \\
\hline
\end{tabular}

\section{B. Unemployment ${ }^{31}$}

\begin{tabular}{|ccccc|}
\hline & ADF(BIC) & ADF(AIC) & ADF(LM) & PP(4) \\
\hline Por & -1.791 & -1.791 & -1.791 & -0.196 \\
Swe & -1.394 & -1.394 & -1.394 & -3.280 \\
Fin & -0.882 & -0.882 & -0.882 & -2.626 \\
N1 & -1.687 & -1.687 & -1.687 & -2.416 \\
Ita & -0.768 & -0.768 & -0.768 & -0.627 \\
Spa & -1.080 & -1.080 & -1.080 & -0.985 \\
Sui & -1.993 & -1.993 & -1.993 & -2.809 \\
Uk & -0.059 & -0.059 & -0.059 & -2.487 \\
Ger & -0.981 & -0.981 & -0.981 & -1.222 \\
Nw & $-4.092^{* *}$ & $-4.092^{* *}$ & $-4.092^{* *}$ & $-7.794 * * *$ \\
Fra & -2.494 & -2.494 & -2.494 & -1.722 \\
\hline
\end{tabular}

Adf(BIC) refers to the Augmented Dickey-Fuller test statistics (including a consntant term)with lag order selected through the Bayesian Information Criterion.

Adf(AIC) refers to the Augmented Dickey-Fuller test statistics (including a constant term) with lag order selected though the Akaike Information Criterion.

$\operatorname{Adf}(\mathrm{KM})$ refers to the Augmented Dickey-Fuller test statistics (including a constant term) with lag order selected through the autocorrelation Lagrange Multiplier test.

PP(4) refers to the non parametric test statistics of Phillips-Perron with a Newey-West window equal to 4.

*indicates rejection of the null of a unit root at the $10 \%$ significance level.

**indicates rejection of the null of a unit root at the 5\% significance level.

***indicates rejection of the null of a unit root at the $1 \%$ significance level.

\footnotetext{
${ }^{31}$ We use here the logistic transformation i.e. $\ln \left(x_{t} /\left(1-x_{t}\right)\right.$, of the unemployment rate since unit root tests require unbounded variables.
} 


\section{Appendix 2. Selected Models}

Switzerland: Selected Model $m=2, p=1$

\begin{tabular}{lccc} 
Equation & Autocorrelation & ARCH & Markov Stability \\
$\Delta U$ & 36.50 & $0.85^{* *}$ & 11.29 \\
$\Delta p$ & 59.20 & 32.70 & 28.85 \\
system & 13.15 & 20.60 & 25.72 \\
\multicolumn{2}{l}{ Transition Matix: $\left[\begin{array}{ll}0.9291 & 0.0913 \\
0.0709 & 0.9087\end{array}\right]$} &
\end{tabular}

Germany: Selected Model: $\mathrm{m}=1, \mathrm{p}=1$

\begin{tabular}{lccc} 
Equation & Autocorrelation & ARCH & Markov Stability \\
$\Delta U$ & 26.57 & 16.27 & $2.58^{* *}$ \\
$\Delta p$ & $0.26^{* *}$ & 42.83 & $0.56^{* *}$ \\
system & 16.53 & 25.53 & $0.65^{* *}$ \\
\multicolumn{2}{l}{ Transition Matix: $\left[\begin{array}{ll}0.9254 & 0.2400 \\
0.0746 & 0.7600\end{array}\right]$}
\end{tabular}

The United Kingdon: Selected Model: $\mathrm{m}=2, \mathrm{p}=4$

$\begin{array}{lccc}\text { Equation } & \text { Autocorrelation } & \text { ARCH } & \text { Markov Stability } \\ \Delta U & 64.98 & 20.65 & 64.20 \\ \Delta p & 31.62 & 42.91 & 53.07 \\ \text { system } & 18.11 & 4.21^{* *} & 64.24\end{array}$

Transition Matix: $\left[\begin{array}{ll}0.7343 & 0.2882 \\ 0.2658 & 0.7118\end{array}\right]$

Portugal: Selected Model: $\mathrm{m}=1, \mathrm{p}=2$

$\begin{array}{lccc}\text { Equation } & \text { Autocorrelation } & \text { ARCH } & \text { Markov Stability } \\ \Delta U & 24.21 & 74.08 & 26.68 \\ \Delta p & 60.59 & 7.04 & 17.20 \\ \text { system } & 25.93 & 8.80 & 37.29\end{array}$

Transition Matix: $\left[\begin{array}{ll}0.7573 & 0.3278 \\ 0.2427 & 0.6722\end{array}\right]$ 
Spain: Selected Model: $\mathrm{m}=1, \mathrm{p}=1$

$\begin{array}{lccc}\text { Equation } & \text { Autocorrelation } & \mathrm{ARCH} & \text { Markov Stability } \\ \Delta U & 13.47 & 44.50 & 50.70 \\ \Delta p & 6.90^{*} & 6.50 \% & 15.11 \\ \text { system } & 19.01 & 67.88 & 19.86\end{array}$

Transition Matix: $\left[\begin{array}{ll}0.8382 & 0.1366 \\ 0.1618 & 0.8644\end{array}\right]$

France: Selected Model: $\mathrm{m}=1, \mathrm{p}=1$

$\begin{array}{lccc}\text { Equation } & \text { Autocorrelation } & \text { ARCH } & \text { Markov Stability } \\ \Delta U & 10.60 & 83.11 & 72.25 \\ \Delta p & 84.48 & 54.31 & 47.82 \\ \text { system } & 34.16 & 13.93 & 70.40\end{array}$

Transition Matix: $\left[\begin{array}{ll}0.8927 & 0.1041 \\ 0.1073 & 0.8986\end{array}\right]$

Sweden: Selected Model: $\mathrm{m}=1, \mathrm{p}=1$

$\begin{array}{lccc}\text { Equation } & \text { Autocorrelation } & \text { ARCH } & \text { Markov Stability } \\ \Delta U & 7.83^{*} & 43.94 & 13.02 \\ \Delta p & 4.12^{*} & 21.23 & 97.53 \\ \text { system } & 9.42^{*} & 26.07 & 21.66\end{array}$

Transition Matix: $\left[\begin{array}{ll}0.5943 & 0.0655 \\ 0.4057 & 0.9345\end{array}\right]$

Norway: Selected Model: $\mathrm{m}=1, \mathrm{p}=1$

$\begin{array}{lccc}\text { Equation } & \text { Autocorrelation } & \text { ARCH } & \text { Markov Stability } \\ \Delta U & 57.52 & 29.92 & 40.14 \\ \Delta p & 0.50^{* *} & 0.27 * * & 19.29 \\ \text { system } & 2.30^{* *} & 16.07 & 24.11\end{array}$


Transition Matix: $\left[\begin{array}{ll}0.8088 & 0.2146 \\ 0.1912 & 0.7854\end{array}\right]$

Finland: Selected Model: $\mathrm{m}=1, \mathrm{p}=4$

Equation Autocorrelation

$\Delta U$

14.99

$\Delta p$

10.02

system

36.83

Transition Matix: $\left[\begin{array}{cc}0.9008 & 0.3677 \\ 0.992 & 0.6323\end{array}\right]$

Italy: Selected Model: $\mathrm{m}=1, \mathrm{p}=4$

Equation Autocorrelation

$\Delta U$

$3.93^{*}$

$\Delta p$

35.20

system

23.03
$\mathrm{ARCH}$

31.14

72.08

59.15
Markov Stability

$8.00 *$

9.56*

$8.92 *$

Transition Matix: $\left[\begin{array}{ll}0.8661 & 0.2967 \\ 0.1339 & 0.7033\end{array}\right]$

The Netherlands: Selected Model: $\mathrm{m}=2, \mathrm{p}=1$

Equation Autocorrelation

$\Delta U$

$\Delta p$

$0.28 *$

$8.34 *$

system

$5.66 *$
$\mathrm{ARCH}$

13.16

71.16

43.55

$\mathrm{ARCH}$

$0.74 * *$

11.86

7.60*
Markov Stability

53.40

64.45

70.10

Transition Matix: $\left[\begin{array}{cc}0.9302 & 0.191 \\ 0.070 & 0.809\end{array}\right]$ 


\section{Appendix 3. Smoothed Recession Probabilities}

Figure 3a. Smoothed Recession Probabilities
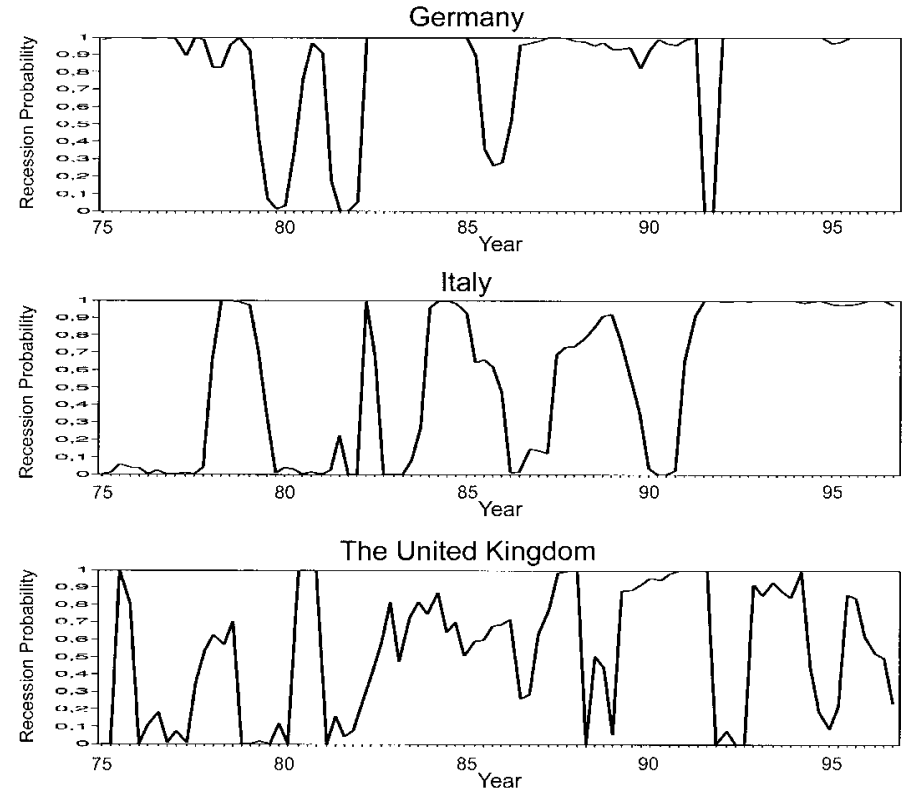

Figure 3b. Smoothed Recession Probabilities
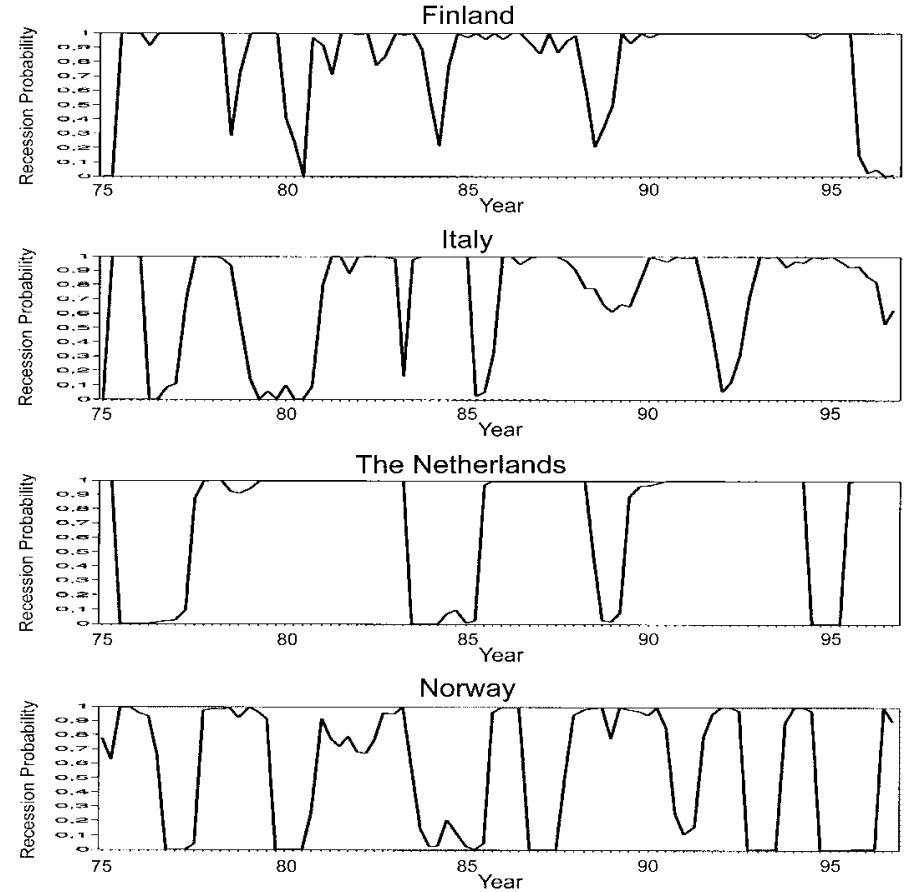
Figure 3c. Smoothed Recession Probabilities
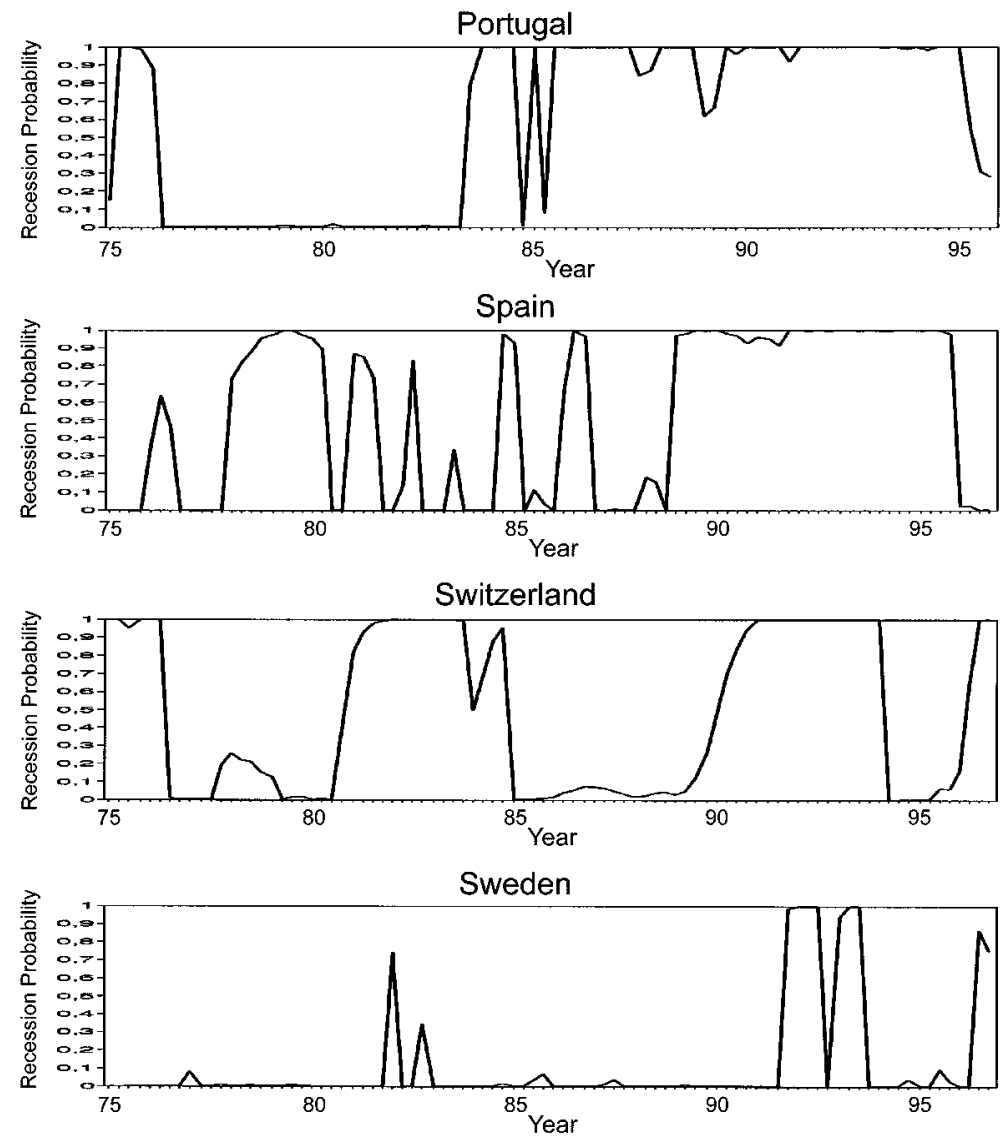

\section{Appendix 4: Business Cycles Turning Points Dating}

\begin{tabular}{|l|l|l|l|l|}
\hline & Germany & France & The UK & Italy \\
\hline Peak & $80 \mathrm{M} 2$ & $76 \mathrm{M} 12$ & $79 \mathrm{M} 4$ & $77 \mathrm{M} 1$ \\
\hline Trough & $82 \mathrm{M} 10$ & $77 \mathrm{M} 10$ & $81 \mathrm{M} 2$ & $77 \mathrm{M} 12$ \\
\hline Peak & $86 \mathrm{M} 5$ & $79 \mathrm{M} 9$ & $83 \mathrm{M} 12$ & $80 \mathrm{M} 3$ \\
\hline Trough & $86 \mathrm{M} 12$ & $81 \mathrm{M} 1$ & $84 \mathrm{M} 8$ & $83 \mathrm{M} 3$ \\
\hline Peak & $91 \mathrm{M} 4$ & $82 \mathrm{M} 3$ & $90 \mathrm{M} 3$ & $89 \mathrm{M} 12$ \\
\hline Trough & & $82 \mathrm{M} 10$ & $92 \mathrm{M} 4$ & \\
\hline Peak & & $84 \mathrm{M} 2$ & & \\
\hline Trough & & $85 \mathrm{M} 2$ & & \\
\hline Peak & & $92 \mathrm{M} 1$ & & \\
\hline
\end{tabular}

Dates are extracted from figures 1 to 7 in Artis, Kontolemis and Osborn (1997) 


\section{Appendix 5. Synchronization Indicators}

Figure 1. Desynchronization Indicator I1

France
Germany
Italy
Spain
Firland
Norway
Portugal
The Netherlands
The Urited Kingdom
Switzerland
Sweden

\begin{tabular}{|cccccc|} 
France & Germany & Italy & Spain & Firland & Norway \\
\hline- & 0.60071 & 0.61222 & 0.59019 & 0.54158 & 0.48697 \\
0.68071 & - & 0.76163 & 0.56182 & 0.70643 & 0.49720 \\
0.61222 & 0.76163 & - & 0.57104 & 0.73125 & 0.53212 \\
\hline 0.59019 & 0.56182 & 0.57104 & - & 0.66783 & 0.53750 \\
0.54158 & 0.70643 & 0.73125 & 0.66783 & - & 0.57343 \\
0.49597 & 0.49720 & 0.53212 & 0.53750 & 0.57343 & $*$ \\
\hline 0.70430 & 0.72319 & 0.69765 & 0.58873 & 0.66793 & 0.55575 \\
0.45452 & 0.61406 & 0.61681 & 0.55527 & 0.69480 & 0.58848 \\
0.53369 & 0.67181 & 0.60728 & 0.54513 & 0.63023 & 0.42670 \\
0.53154 & 0.52092 & 0.56806 & 0.54250 & 0.57325 & 0.59391 \\
0.48677 & 0.41425 & 0.36870 & 0.55125 & 0.37599 & 0.44962 \\
\hline
\end{tabular}

\begin{tabular}{|c|c|c|c|c|c|}
\hline & Portugal & The NL & The UK & Switzerland & Saveden \\
\hline France & 0.70430 & 0.45452 & 0.53369 & 0.53154 & 0.48677 \\
\hline Germany & 0.72319 & 0.61406 & 0.67181 & 0.52092 & 0.41425 \\
\hline Italy & 0.69765 & 0.61681 & 0.60728 & 0.56806 & 0.36870 \\
\hline Spain & 0.58873 & 0.55527 & 0.54513 & 0.54250 & 0.55125 \\
\hline Finland & 0.66793 & 0.69480 & 0.60023 & 0.57325 & 0.37599 \\
\hline Norway & 0.56575 & 0.58848 & 0.42670 & 0.59391 & 0.44962 \\
\hline Portugal & - & 0.56660 & 0.59960 & 0.48231 & 0.39681 \\
\hline The Netherlands & 0.56660 & - & 0.53001 & 0.59003 & 0.33305 \\
\hline The United Kingdom & 0.59960 & 0.53801 & $\therefore$ & 0.50362 & 0.56465 \\
\hline Switzerland & 0.48231 & 0.59000 & 0.50362 & - & 0.55700 \\
\hline Swaden & 0.39581 & 0.33305 & 0.56465 & 0.55700 & - \\
\hline
\end{tabular}

Figure 2. Desynchronization Indicator I2

France
Germary
Italy
Spain
Finland
Norway
Pertugal
The Netherlands
The Uniled Kingdom
Switzerland
Sweden

\begin{tabular}{|c|c|c|c|c|c|}
\hline France & Germany & Italy & Spain & Finland & Norwey \\
\hline- & 0.59420 & 0.50725 & 0.47826 & 0.39130 & 0.39130 \\
\hline 0.58420 & - & 0.65217 & 0.63623 & 0.63768 & 0.40580 \\
\hline 0.50725 & 0.65217 & . & 0.49275 & 0.68116 & 0.42029 \\
\hline 0.47826 & 0.53623 & 0.49275 & - & 0.60870 & 0.50725 \\
\hline 0.39130 & 0.63768 & 0.68116 & 0.60970 & . & 0.49275 \\
\hline 0.39130 & 0.40580 & 0.42029 & 0.50725 & 0.49275 & - \\
\hline 0.58420 & 0.68667 & 0.65217 & 0.62174 & 0.62319 & 0.47826 \\
\hline 0.36232 & 0.57971 & 0.56522 & 0.53523 & 0.65217 & 0.56522 \\
\hline 0.37681 & 0.55072 & 0.40580 & 0.37681 & 0.44928 & 0.24638 \\
\hline 0.37681 & 0.42029 & 0.43478 & 0.49275 & 0.50725 & 0.50725 \\
\hline 0.40580 & 0.37681 & 0.26087 & 0.52174 & 0.31884 & 0,37681 \\
\hline
\end{tabular}

Germary
Italy
Spain
Finland
Norway
Portugal
The Netherlands
The United Kingdom
Switzerland
Swedan

\begin{tabular}{|ccccc|}
\hline Portugal & The NL & The UK & Switzerland & Sweden \\
\hline 0.66657 & 0.57971 & 0.65072 & 0.42029 & 0.37681 \\
0.65217 & 0.56522 & 0.40580 & 0.43478 & 0.26087 \\
0.52174 & 0.53623 & 0.37681 & 0.49275 & 0.52174 \\
0.62319 & 0.65217 & 0.44928 & 0.50725 & 0.31884 \\
0.47826 & 0.56522 & 0.24638 & 0.50725 & 0.37681 \\
& 0.53623 & 0.44928 & 0.39130 & 0.33333 \\
0.53623 & - & 0.40580 & 0.52174 & 0.30435 \\
0.44928 & 0.40580 & - & 0.34783 & 0.46377 \\
0.39130 & 0.52174 & 0.34783 & - & 0.52174 \\
0.33333 & 0.30435 & 0.46377 & 0.52174 & - \\
\hline
\end{tabular}


Figure 3. Desynchronization Indicator I3

France
Germany
lialy
Spain
Finland
Norway
Portugal
The Netherlands
The United Kingdom
Switzerland
Sweden

\begin{tabular}{|c|c|c|c|c|c|}
\hline France & Germary & ltaly & Spain & Firland & Norway \\
\hline 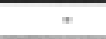 & 0.66667 & 0.60870 & 0.55797 & 0.49275 & 0.48551 \\
\hline 0.66667 & - & 0.73913 & 0.55797 & 0.69665 & 0.45662 \\
\hline 0.60970 & 0.73913 & - & 0.57246 & $0.753 \times 12$ & 0.51449 \\
\hline 0.55797 & 0.55797 & 0.57246 & - & 0.65942 & 0.53623 \\
\hline 0.49275 & 0.69565 & 0.76362 & 0.65942 & - & 0.55797 \\
\hline 0.48551 & 0.45652 & 0.51449 & 053623 & 0.55797 & . \\
\hline D. 68341 & 0,71739 & 0.71739 & 0.56522 & 0.67391 & 0.53623 \\
\hline 0.43478 & 0.60670 & 0.63769 & 0.55797 & 0.69565 & 0.60145 \\
\hline 0.50725 & 0.68116 & 0.57971 & 0.51449 & 0.59420 & 0.38406 \\
\hline 0.48551 & 0.48551 & 0.54348 & 0.55072 & 0.57246 & 0.57971 \\
\hline 0.48551 & 0.41304 & 0.34068 & D. 55072 & 0.36957 & 0.42029 \\
\hline
\end{tabular}

\begin{tabular}{|c|c|c|c|c|c|}
\hline & Portugal & The NL. & The UK & Swizerland & Swoden \\
\hline France & 0.68841 & 0.43478 & 0.50725 & 0.48551 & 0.49551 \\
\hline Germany & 0.71739 & 0.60670 & 0.68116 & 0.48551 & 0.41304 \\
\hline Italy & 0.71739 & 0.63768 & 0.57971 & 0.54348 & 0.34068 \\
\hline Spain & 0.56522 & 0.55797 & 0.51449 & 0.56072 & 0.55072 \\
\hline Finland & 0.67391 & 0.69565 & 0.59420 & 0.57246 & 0.36957 \\
\hline Norway & 0.53623 & 0.60145 & 0.38406 & 0.57971 & 0.42029 \\
\hline Portugeal & - & 0.57246 & D. 58696 & 0.46377 & 0.37681 \\
\hline The Notherlands & 0.57246 & - & 0.52174 & 0.57246 & 0.31159 \\
\hline The United Kingdom & 0.58696 & 0.52174 & - & 0.50000 & 0.57246 \\
\hline Switzerland & 0.46377 & 0.57246 & 0.50000 & - & 0.57971 \\
\hline Swodan & 0.37681 & 0.31159 & 0.57246 & 0.57971 & $=$ \\
\hline
\end{tabular}

Figure 4. Desynchronization Indicator I4

France
Germany
ltaly
Spain
Finland
Norway
Portugal
The Netherlands
The United Kingdom
Switzerland
Sweden

France
Germany
Italy
Spain
Finland
Norway
Portugal
The Netherlands
The United Kingdem
Switzerland
Sweden

\begin{tabular}{|c|c|c|c|c|c|}
\hline France & Germany & Italy & Spain & Finland & Narway \\
\hline- & 5.85714 & 3.88889 & 4.12500 & 4.50000 & 3.37500 \\
\hline 5.85714 & + & 6. 42457 & 5.28571 & 7.33333 & 3.50000 \\
\hline 3.88889 & 6.42857 & - & 4,85714 & 5.87500 & 3.62500 \\
\hline 4.12500 & 5.28571 & 4.65714 & - & 4.20000 & 3. 50000 \\
\hline 4.50000 & 7.33323 & 5.87500 & 4.20000 & . & 3.40000 \\
\hline 3.37500 & 3.50000 & 3.62500 & 3.50000 & 3.40000 & - \\
\hline 5.87514 & 5.75000 & 5.62500 & 5.14286 & 5.37500 & 3.30000 \\
\hline 5.00000 & 6. 64667 & 6.50000 & 4,11111 & 7.50000 & 3.90000 \\
\hline 2.36364 & 3.80000 & 3.11111 & 3.71429 & 3.10000 & 1.70000 \\
\hline 4.33333 & 3.62500 & 4.28571 & 4.25000 & 5.83333 & 3.50000 \\
\hline 3.11111 & 3.25000 & 2.25000 & 3.27273 & 2.75000 & 2.60000 \\
\hline Portugal & The NL. & The UK & Switzerland & Sweden & \\
\hline 5.85714 & 5.00000 & 2.36364 & 4.33333 & 3.11111 & \\
\hline 5.75000 & 6.66667? & 3.80000 & 3.62500 & 3.25000 & \\
\hline 5.62500 & 6.50000 & 3.11111 & 4.28571 & 2.25000 & \\
\hline 5.14286 & 4.11111 & 3.71429 & 4.25000 & 3.27273 & \\
\hline 5.37500 & 7.50000 & 3.10000 & 5.83333 & 2.75000 & \\
\hline 3.30000 & 3.90000 & 1.70000 & 3.50000 & 2.60000 & \\
\hline = & 9.25000 & 3.44444 & 3.85714 & 3.28571 & \\
\hline 9.25000 & - & 3.11111 & 6.00000 & 3.50000 & \\
\hline 3.44444 & 3.11111 & . & 240000 & 2.90009 & \\
\hline 3.85714 & 6.00000 & 2.40000 & - & 4.50000 & \\
\hline 3.28627 & 3.50000 & 2.90909 & 450000 & . & \\
\hline
\end{tabular}

